\title{
RECURSOS ADMINISTRATIVOS, PETICIONES Y PROCEDIMIENTOS EN TIEMPOS DE COVID-19: PRIMEROS COMENTARIOS A LA LEY N 19.879
}

\section{ADMINISTRATIVE APPEALS, PETITIONS AND PROCEDURES IN TIMES OF CO- VID-19: FIRST COMMENTS TO LAW No. 19,879}

\section{RECURSOS ADMINISTRATIVOS, SOLICITAÇOES E PROCEDIMENTOS NOS TEM- POS DO COVID-19: PRIMEIROS COMENTÁRIOS Á LEI Nº 19.879}

Rodrigo Díaz Inverso

RESUMEN. Las relaciones entre la Administración y los administrados se han visto notoriamente afectadas por la crisis sanitaria provocada por el COVID-19. La Ley No 19.879 de 30 de abril de 2020 procuró brindar las garantías suficientes a los particulares a efectos de evitar que la pandemia provocara una indefensión en materia de recursos y peticiones administrativas, así como otros aspectos referidos a los procedimientos administrativos. Se analiza el ámbito de aplicación del texto legal y las distintas soluciones normativas que surgen del mismo.

PALABRAS CLAVES. Recursos. Peticiones. Procedimiento administrativo. Feria judicial extraordinaria. Plazos.

ABSTRACT. Relationships between the Administration and the people have been notoriously disturbed due to the health crisis caused by COVID-19. Law No. 19,879 enacted on April 30, 2020 sought to provide specific guarantees in order to prevent the pandemic from causing defenselessness in terms of administrative petitions and appeals, as well as other aspects related to administrative procedures. The scope of the legal text and different regulatory solutions arising thereof are analyzed.

KEY WORDS. Appeals. Petitions. Administrative procedures. Extraordinary judicial recess. Terms.

RESUMO. As relações entre a administração e os administrados foram notoriamente afetadas pela crise de saúde causada pelo COVID-19. A Lei n ${ }^{0} 19.879$, de 30 de abril de 2020, procurou fornecer garantias suficientes às pessoas, a fim de evitar que a pandemia

\footnotetext{
* Doctor en Derecho y Ciencias Sociales. Master en Derecho orientación Derecho Internacional Público. Aspirante a Profesor Adscripto en Derecho Administrativo, por la Universidad de la República. Mail: rodrigodiazinverso@hotmail.com
} 
cause indefesa em termos de recursos e solicitações administrativas, além de outros aspectos relacionados aos procedimentos administrativos. $\mathrm{O}$ escopo do texto jurídico e as diferentes soluções regulatórias dele decorrentes são analisados.

PALAVRAS - CHAVES. Recursos. Solicitações. Procedimento Administrativo. Feira judicial extraordinária. Prazos.

\section{INTRODUCCIÓN.-}

En el marco de la pandemia originada por el COVID-19, el 30 de abril de 2020 se promulgó la Ley No 19.879 (en adelante la "Ley") de "Declaración de Feria Judicial Extraordinaria y suspensión de plazos procesales".

En el presente, comentaremos brevemente las disposiciones que refieren a los plazos para interponer recursos administrativos y resolver peticiones por parte de la Administración, así como otras cuestiones que hacen a los procedimientos administrativos.

Al respecto, debemos partir de la base de que la regulación de los procedimientos administrativos es una materia que la Constitución (artículo 318) asigna en forma compartida a la ley y al reglamento (CAJARVILLE PELUFFO, 2008a). Si bien tradicionalmente ha sido regulado por la vía reglamentaria (el Decreto $N^{0} 500 / 991$ y sus antecesores en el ámbito del Poder Ejecutivo y una multiplicidad de reglamentos similares en el ámbito de los restantes sistemas orgánicos, gobiernos departamentales y administraciones descentralizadas por servicio), al sancionarse una ley en sentido orgánico-formal, sus soluciones primarán por sobre las previstas en actos administrativos, en la medida en que no sean compatibles.

\section{RECURSOS Y PETICIONES.-}

a) El plazo para interponer recursos administrativos

El plazo de 10 días, previsto en el artículo 317 de la Constitución, en el artículo 4 de la Ley No 15.869 de 22 de junio de 1987 y el artículo 142 del Decreto No 500/991, se cuenta en días corridos y si vence en día inhábil, el vencimiento acaecerá el día hábil inmediato siguiente. El plazo se suspende en las Ferias Judiciales y la Semana de Turismo.

La innovación de la Ley consiste en declarar suspendidos los plazos de interposición de 
los recursos desde el 14 de marzo (día siguiente al Decreto $N^{\circ}$ 93/020, mediante el cual el Poder Ejecutivo declaró la emergencia sanitaria) y "por el término de duración de la Feria Judicial Extraordinaria".

Cuatro aspectos de la solución legal entendemos necesario resaltar.

En primer lugar, que la solución debe considerarse ajustada a la Constitución, en la medida en que se ha entendido que el plazo de 10 días es un plazo mínimo, garantizado por la Carta, pero que puede resultar mayor si la ley así lo dispone (DURÁN MARTÍNEZ, 2007). De hecho, las suspensiones por las Ferias Judiciales ordinarias, la Semana de Turismo o el hecho de que si el plazo vence en día inhábil se prorrogue al día hábil inmediato siguiente, son hipótesis de extensión del plazo que se han admitido desde siempre pacíficamente, incluso por la jurisprudencia de la Suprema Corte de Justicia.

En segundo lugar, que en materia de recursos administrativos, el ámbito de aplicación subjetivo de la Ley comprende a todos los órganos públicos, estatales o no. Por lo tanto, todo órgano estatal que dicte un acto en ejercicio de función administrativa, cualquiera sea la persona jurídica estatal a la que pertenezca, quedará comprendido dentro de sus disposiciones, así como también las personas públicas no estatales.

Cabe destacar respecto al ámbito objetivo de aplicación de la Ley, que el artículo 4 literal a), refiere a la interposición de recursos contra "las resoluciones", lo que podría dar lugar a interpretar que sólo comprende a las resoluciones en sentido estricto, esto es, los actos administrativos de efectos particulares y concretos, según la definición de la dogmática que es recogida en el artículo 120 del Decreto $N^{\circ}$ 500/991. De adoptarse esa solución, quedarían por fuera de la suspensión de los plazos los recursos administrativos contra los reglamentos, en tanto no ingresan dentro del concepto técnico de "resoluciones".

Sin embargo, la generalidad de la norma, su finalidad claramente tuitiva del derecho de las personas a recurrir los actos administrativos y acceder a la jurisdicción, así como la pauta de interpretación que brinda el artículo 6 de la Ley, nos lleva a sostener que la utilización del término "resoluciones" debe tomarse en este caso como sinónimo de acto administrativo, abarcando todas sus especies.

Por otra parte, el artículo 4 contiene una pauta general en su acápite (en la cual se refiere a la suspensión de "todos los plazos establecidos para los procesos en los que se pretende la anulación de actos dictados por personas públicas estatales y no estatales”) siendo el literal "a" una concreción de esa disposición general, con fines fundamentalmente acla- 
ratorios. En consecuencia, aunque entendiéramos que el literal "a" refiere únicamente a actos subjetivos y particulares ("resoluciones"), la redacción amplia del acápite ("actos") nos lleva a reafirmar la conclusión de que los reglamentos también quedan comprendidos dentro de la suspensión.

En tercer lugar, que se dispuso una suspensión, razón por la cual el plazo no se interrumpió y los días que hubieren corrido con anterioridad al 14 de marzo deben ser incluidos en el cómputo del plazo de 10 días, una vez que finalice la suspensión. Por tanto, el plazo no se reinicia desde cero si ya había comenzado a correr, por notificación personal o publicación en el Diario Oficial previo al 14 de marzo.

En cuarto lugar, debe señalarse que la fecha de finalización de esta Feria Judicial Extraordinaria reviste una nota especial respecto a las Ferias Judiciales ordinarias, en las cuales las fechas de comienzo y finalización están previstas expresamente en la ley (del 25 de diciembre al 31 de enero la denominada Feria Judicial Mayor, y del $1^{\circ}$ al 15 de julio, la Feria Judicial Menor).

En este caso, la finalización depende de sendos actos administrativos dictados por la Suprema Corte de Justicia (SCJ) y el Tribunal de lo Contencioso Administrativo (TCA), según corresponda, de conformidad con la potestad que les reconoce el artículo 1 de la Ley a ambos órganos, como parte de la "superintendencia administrativa" que la Constitución les asigna en sus respectivos ámbitos competenciales (artículos 239 numeral 2 y 320 respectivamente).

Ahora bien, siendo dos órganos jerarcas máximos de sus respectivos sistemas, ¿cuál de las dos fechas deberíamos tomar en consideración para fijar el punto de finalización de la suspensión del plazo para interponer recursos administrativos y, por consiguiente, el reinicio del cómputo?

El punto es importante ya que mientras que la SCJ dispuso que la Feria Judicial Extraordinaria finalizara el día 15 de mayo (Resolución No 29/2020, artículo 7), el TCA la extendió hasta el día 31 del mismo mes, según Acordadas № 8, 9, 10 y 11 del 2020. Por lo tanto, fijar una u otra fecha como punto final de la suspensión determinará que un administrado haya recurrido en forma correcta o extemporánea.

Atento a que la Ley no resuelve expresamente el asunto, consideramos que la suspensión a los efectos de interponer recursos administrativos estuvo vigente hasta la fecha en la cual el TCA mantuvo su Feria Judicial Extraordinaria (esto es, 31 de mayo de 2020), por 
las razones que a continuación exponemos.

En primer lugar, porque los recursos administrativos (y el consiguiente agotamiento de la vía administrativa) están creados por la Constitución como un presupuesto procesal para el acceso a la jurisdicción del TCA, a efectos de reclamar la nulidad de un acto administrativo. Esa es su finalidad y no otra, en tanto su efectividad como medio de defensa o garantía es harto cuestionable (CAJARVILLE PELUFFO, 2008b), y la exigencia constitucional de su interposición como forma de agotar la vía administrativa y poder acceder a la jurisdicción contencioso-anulatoria responde a una transacción entre partidos políticos, en un contexto histórico determinado, más que a una justificación racional en clave de garantías (DURÁN MARTÍNEZ, 2017).

Por lo tanto, resulta más lógico vincular la finalización de la suspensión del plazo para recurrir, al levantamiento de la feria que dispuso el TCA y no el Poder Judicial, ya que ninguna acción que se interponga ante éste último tiene como presupuesto haber recurrido previamente el acto administrativo. La única salvedad que podría plantearse sería por parte de aquellos que aun postulan que la acción reparatoria patrimonial respecto de daños provocados por un acto administrativo requiere el previo agotamiento de la vía administrativa, posición absolutamente minoritaria en la dogmática pero respecto de la cual la jurisprudencia ha sido oscilante.

En segundo lugar, la interpretación postulada es la que mejor se acompasa al principio de tutela jurisdiccional efectiva, especialmente en su dimensión vinculada al acceso a la jurisdicción.

Cabe destacar que la Ley fijó en su artículo 6 una pauta hermenéutica clara al momento de interpretarla: debe siempre preferirse la interpretación que garantice "más eficazmente el acceso pleno a la efectiva tutela jurisdiccional o administrativa, y resulte ajustada a los principios del debido procedimiento o proceso, contradicción y pro actione".

En el caso concreto, evidentemente esa solución (esto es, la que más satisface los criterios impuestos por el legislador en cuanto a permitir al administrado llevar su caso ante el órgano jurisdiccional) es la de vincular la suspensión del plazo para interponer recursos administrativos al plazo de duración de la Feria Judicial Extraordinaria que dispuso el TCA, por ser con la que tiene una natural conexión (al extremo de ser un presupuesto procesal para accionar válidamente ante dicha jurisdicción) y por haber sido más extensa que la del Poder Judicial. Por ende, ante la duda que pudo generar en los administrados, debemos optar por la solución más garantista y que mejor efectiviza el goce del derecho a 
la tutela jurisdiccional, permitiendo que el afectado por un acto administrativo tenga una instancia efectiva de revisión jurisdiccional.

Otro punto importante a destacar es que si el afectado por el acto administrativo interpuso recursos administrativos mientras el plazo se encontraba suspendido, éstos serán perfectamente válidos y eficaces, en la medida en que la suspensión está prevista en su beneficio. En ese sentido, es equiparable al caso de quien recurre durante una Feria Judicial ordinaria o en Semana de Turismo. Que el plazo esté suspendido no significa que el medio impugnativo no pueda movilizarse válidamente.

Por último, corresponde indicar que la suspensión del plazo para recurrir dispuesta por la Ley comprende a los recursos previstos contra actos de las personas públicas no estatales en sus distintas leyes orgánicas. Con una multiplicidad de soluciones de derecho positivo, los actos de estas personas jurídicas deben ser, en la mayoría de los casos, recurridos ante el propio organismo (una suerte de agotamiento de la vía interna) y posteriormente impugnados ante al Poder Judicial, incluso cuando no existe una solución legal expresa.

En este caso debe hacerse notar que el plazo de suspensión de los plazos para recurrir sí quedaría vinculado a la Feria Judicial Extraordinaria que dispuso la SCJ, en la medida en que los actos de las personas públicas no estatales no ingresan dentro de la esfera competencial del TCA y, por ende, no rige el razonamiento antes expuesto, en cuanto a la conexión del recurso con dicha jurisdicción. Podría, de todas formas, plantearse la duda de si correspondería en virtud del principio de tutela jurisdiccional efectiva a que refiere el artículo 6, hacer una interpretación como la postulada para los actos administrativos stricto sensu; de todas formas, resulta sin dudas más cuestionable, en la medida en que la ajenidad de las personas públicas no estatales a la competencia del TCA es evidente y pacíficamente aceptada.

Por tal motivo, consideramos que la suspensión del plazo para recurrir los actos de las personas públicas no estatales finalizó el 15 de mayo, al reanudarse la actividad jurisdiccional del Poder Judicial.

b) La forma de presentación de recursos y peticiones

El artículo 5.1 de la Ley establece que "durante la vigencia de la emergencia sanitaria dispuesta por el Poder Ejecutivo, se podrá interponer cualquier escrito de petición o recurso administrativo (...) a través de comunicación electrónica a las casillas institucionales del órgano destinatario o emisor del acto cuestionado o su delegante". 
Cabe destacar que la utilización de medios electrónicos para presentar peticiones y recursos frente a la Administración ya se encuentran previstos en nuestro derecho desde el propio Decreto $\mathrm{N}^{0}$ 500/991 (artículos 19, 154 y 157), sin perjuicio de que también contaba con respaldo legal por los artículos 694 a 697 de la Ley $\mathrm{N}^{\mathrm{o}} 16.736$ de 5 de enero de 1996. A su vez, en términos generales, el artículo 75 de la Ley $N^{0} 19.355$ de 19 de diciembre de 2015 había consagrado la obligación de las entidades públicas de "constituir domicilio electrónico a los efectos del relacionamiento electrónico entre sí y con las personas". Por lo tanto, la solución legal no constituye exactamente una innovación, sin perjuicio de valorarse en términos positivos a efectos de brindar mayor certeza a los administrados.

Como afirma CAJARVILLE PELUFFO (2008b), lo importante de estos medios de interposición de recursos administrativos (distintos de la presentación tradicional en papel en forma presencial), es que tengan la aptitud suficiente para que el destinatario (la Administración) conozca la voluntad del administrado de recurrir (por ser esa la esencia del recurso) y que brinden certeza respecto a la fecha de su interposición (por cuanto una recurso fuera de plazo, deja de ser un recurso).

La casuística puede ser infinita, en cuanto a las múltiples controversias que se podrán generar. De todas formas, partiendo de lo dicho y del principio rector del artículo 6 de la Ley, lo que la Administración deberá tener en cuenta para considerar la correcta interposición de un recurso mediante estos medios electrónicos es que: (i) haya sido presentado dentro del plazo constitucional; (ii) el emisor del correo electrónico se identifique claramente y, en caso que actúe en representación de un tercero, que invoque expresamente dicha circunstancia, aunque no la acredite en el mismo acto; (iii) manifieste en forma clara (sin necesidad de exigirle términos sacramentales) su voluntad de recurrir un acto administrativo; (iv) individualice el acto administrativo que recurre, con los datos que tenga en su poder.

La propia Ley establece que la ratificación de firmas recién se podrá exigir recién al finalizar la emergencia sanitaria. Por lo tanto, la solución del artículo 157 Decreto $\mathrm{N}^{\mathrm{o}}$ 500/991 (y los restantes reglamentos de procedimiento administrativo, en el ámbito de la descentralización funcional y territorial) en cuanto a exigir que el recurrente ratifique la firma dentro de los diez días hábiles siguientes, no será de aplicación para los recursos interpuestos durante el período de suspensión establecido por la ley. Sólo cuando el Poder Ejecutivo deje sin efecto la emergencia sanitaria, se podrá restablecer dicha exigencia.

Debe tenerse presente que los recursos administrativos requieren firma letrada (art. 37 del 
Decreto-ley $\mathrm{N}^{\mathrm{0}}$ 15.524), pero la jurisprudencia del TCA entiende que no es un requisito de validez, en tanto la ley no establece una consecuencia por su omisión. Por lo tanto, un recurso administrativo interpuesto por correo electrónico sin firma letrada no constituye un obstáculo para el correcto agotamiento de la vía administrativa.

El artículo 156 del Decreto No 500/991 establece un plazo de diez días para salvar la omisión de firma letrada, bajo apercibimiento de archivo. Dicha solución reglamentaria no es aplicable durante la vigencia de la emergencia sanitaria.

Cualquier otra exigencia que se le plantee al recurrente o al peticionario deberá serle comunicada por correo electrónico y permitirse (en la medida en que sea posible) que lo subsane por esa vía, difiriendo cualquier instancia presencial al cese efectivo de la emergencia sanitaria por parte del Poder Ejecutivo.

c) El plazo para resolver recursos y peticiones

Los plazos para resolver los recursos administrativos dependen de cuántos hayan sido interpuestos, correspondiendo un mínimo de 150 días (sólo revocación o reposición), 200 días (revocación y jerárquico, revocación y anulación o reposición y apelación) y 250 (revocación, jerárquico y anulación). En el caso de las peticiones, el plazo para resolver es de 150 días.

En la medida en que estos plazos no son verdaderas garantías para los administrados sino privilegios excesivos para la Administración, la solución legal parece acertada: los plazos no se suspenden y por lo tanto si la Administración no resuelve se tendrá por configurada la denegatoria ficta.

En el caso de las peticiones, si la denegatoria ficta se configuró durante la vigencia de la Feria Judicial Extraordinaria, el plazo para recurrirla recién comenzó a contabilizarse una vez que ésta finalizó.

Por su parte, si se configuró el agotamiento de la vía administrativa durante la Feria Judicial Extraordinaria, sea en forma expresa o en forma ficta, el plazo para acudir ante el TCA a interponer la acción de nulidad, quedó suspendido por el artículo 4 de la Ley.

\section{PROCEDIMIENTOS ADMINISTRATIVOS.-}

a) El plazo para evacuar vista 
Como es unánimemente aceptado por la dogmática y la jurisprudencia, el otorgamiento de vista previa constituye una manifestación del derecho de defensa y del debido procedimiento, de raigambre constitucional.

La solución legal en este caso consiste en no suspender el plazo sino disponer que "los plazos para evacuar vistas conferidas comenzarán a contarse desde que se produzca el acceso al expediente administrativo completo en soporte electrónico por parte del interesado" (artículo 5.2).

Es decir que en la medida en que la Administración facilite al interesado una copia completa del expediente en formato electrónico, la vista se considera correctamente otorgada y el plazo para evacuarla comienza a correr, debiendo permitirse que el interesado haga su presentación también por medios electrónicos, para lo cual se lo deberá informar adecuadamente. Esto supone entonces que:

- el plazo no correrá si el administrado es intimado a concurrir a tomar vista en las oficinas de la Administración, cualquiera sea el medio utilizado. En tal caso, la no comparecencia no podrá tener el efecto de notificación ficta prevista en el artículo 91 del Decreto $\mathrm{N}^{\mathrm{o}}$ 500/991 y sus similares en los reglamentos de las administraciones descentralizadas, en la medida en que la solución legal exige el acceso efectivo al expediente, no admitiéndose una notificación ficta (en donde, dicho acceso no se produce en la realidad). Esto sin embargo quedaría subsanado si el administrado, ante la intimación, concurre a la oficina, accede al expediente y se notifica, en cuyo caso correrá el plazo de la vista.

- el plazo no correrá si la Administración remite al interesado una copia parcial del expediente. En tal sentido, algunas dependencias tienen la práctica de conferir vista únicamente de las últimas actuaciones del trámite (ejemplo, un informe técnico) pero no del expediente íntegro. El acceso a la actuaciones debe realizarse en forma completa y sin cortapisas (salvo excepciones legalmente establecidas, al amparo de algunas de las excepciones previstas en la Ley $\mathrm{N}^{\circ} 18.381$ de 17 de octubre de 2008), por lo que un acceso parcial no haría iniciar el cómputo del plazo. Por ende, será de cargo de la Administración realizar correctamente la notificación para que los plazos efectivamente comiencen a correr.

- tampoco correrá el plazo si no se le informa al interesado, en la propia notificación, las vías disponibles para la presentación electrónica del escrito de evacuación de vista. El propio acto electrónico de notificación debe, además de contener copia completa del ex- 
pediente, informar al administrado respecto a las vías electrónicas disponibles para evacuar la vista que se le confirió (correo electrónico, sitio web, etc.). Si la Administración no le brinda esa información en el mismo acto que lo notifica, el plazo no correrá.

En este caso de las disposiciones relativas al otorgamiento de la vista, pierden vigencia una vez que el Poder Ejecutivo declare el cese de la emergencia sanitaria, en la medida en que así lo dispone el artículo 5.5. Nótese que la finalización de las medidas de excepción en este caso no depende de la Feria Judicial Extraordinaria (como en el plazo para recurrir o para interponer las acciones jurisdiccionales), sino de la decisión del Poder Ejecutivo de cesar el estado de emergencia sanitaria, por lo que serán soluciones de mayor duración temporal.

b) Procedimientos disciplinarios

En este punto debemos conciliar las soluciones de la Ley, con las previstas posteriormente por la Ley $N^{o} 19.883$ de 4 de junio de 2020. La primera dificultad a reseñar es que mientras la primera tiene un ámbito de aplicación muy amplio, la segunda refiere exclusivamente a procedimientos disciplinarios respecto a funcionarios del Poder Ejecutivo.

El artículo 3.1 de la Ley dispone la suspensión de "todos los plazos de prescripción extintiva y caducidad establecidos en la normativa vigente". Por su parte, en el 3.2 excluye de la suspensión (en lo que aquí nos interesa) a: (i) la prescripción de las faltas administrativas; (ii) el plazo previsto en el artículo 165 de la Acordada 7865 ("Estatuto del funcionario judicial") y; (iii) la clausura de los procedimientos disciplinarios de jueces (artículo 113 de la Ley $\mathrm{N}^{\mathrm{o}} 15.750$ )

Con respecto entonces a la prescripción de las faltas disciplinarias, la suspensión no opera. En el caso de las cometidas por los funcionarios de la Administración Central, la Ley $N^{\circ} 19.121$ (artículo 79) establece un plazo de prescripción de seis años (cuando no constituyen delito) y cuando constituyen delito se aplica el plazo de prescripción de éste. Dichos plazos continuaron corriendo con normalidad, a pesar de la emergencia sanitaria, y consideramos que tampoco quedan comprendidas dentro de la suspensión de la Ley $\mathrm{N}^{\mathrm{o}}$ 19.883 , en la medida en que la prescripción no es propiamente un plazo del procedimiento disciplinario (objeto de la suspensión dispuesta por dicho acto legislativa), sino del ejercicio de la potestad disciplinaria; es un plazo sustancial y no procedimental. Por tanto, y realizando una interpretación acorde al principio pro homine, debe entenderse que el plazo de prescripción continúa corriendo. 
Distinto es el caso de la clausura del procedimiento disciplinario, que procede a los dos años a contar desde la resolución que da inicio al sumario para el caso de los funcionarios del Poder Ejecutivo (artículo 78) y que supone la conclusión del procedimiento por falta de resolución en tiempo. Este plazo consideramos que sí queda suspendido por la emergencia sanitaria, en la medida en que ingresa dentro de la suspensión genérica de las caducidades previstas en el artículo 3.1. También debe considerarse comprendido dentro de la suspensión que prevé el artículo 1 de la Ley $N^{\circ} 19.883$ (en su ámbito específico de aplicación: el Poder Ejecutivo), en tanto constituye un plazo máximo de duración del procedimiento disciplinario.

Cabe destacar la curiosidad de que los únicos procedimientos disciplinarios cuya clausura quedó expresamente excluida de la suspensión son los de los funcionarios judiciales (previsto en la Acordada 7865 "Estatuto del funcionario judicial", artículo 165) y de los jueces (artículo 113 de la Ley $N^{0}$ 15.750). Dicha diferenciación entre funcionarios del Poder Judicial (respecto a los cuales el plazo para que opere la clausura no se suspendió) y del resto del Estado (en los cuales el plazo sí fue suspendido) no guarda una fundamentación razonable. Por su parte, atento al ámbito de aplicación de la Ley No 19.883 (funcionarios del sistema orgánico Poder Ejecutivo), las exclusiones antes referidas (vinculadas al Poder Judicial) se mantienen vigentes.

Sin perjuicio de no existir una suspensión general de los plazos procedimentales para funcionarios que no revistan en el Poder Ejecutivo (por ejemplo, el plazo de instrucción de un sumario), corresponde hacer la salvedad en aquellos procedimientos disciplinarios en los cuales debiera practicarse una diligencia cuya realización no pudiera hacerse brindando las garantías del caso para el debido control por parte del administrado. En tal hipótesis (prevista en el artículo 5.3 de la Ley para todos los procedimientos administrativos), el instructor podría dar por suspendido el procedimiento, con noticia al interesado.

De todas formas este instituto debería usarse en forma prudente y fundada, y no simplemente como una suspensión genérica de todos los procedimientos disciplinarios. En especial, y de acuerdo al artículo 5.4, los jerarcas deberán velar por la aplicación racional de este dispositivo.

c) Duración razonable de los procedimientos

La duración razonable del procedimiento administrativo constituye una garantía para el administrado y una obligación para la Administración. 
Sin embargo, no existe un tiempo exacto que permita establecer cuándo estamos ante un procedimiento cuya duración respeta las notas de razonabilidad y cuando no. La jurisprudencia del TCA muestra una saludable tendencia garantista, al ponderar tanto los derechos de las personas como los deberes de la Administración, a partir de las particularidades de los casos concretos, tomando en cuenta los parámetros que fijan los tribunales internacionales de derechos humanos, la conducta del administrado, la complejidad del asunto y la actividad desarrollada por la Administración, entre otros.

El punto sobre el cual llamamos la atención en esta emergencia sanitaria es que atento a que el funcionamiento de la Administración se ha visto indudablemente alterado (funcionarios tele trabajando, regímenes de guardias presenciales mínimas, funcionarios certificados por su edad o por patologías previas), parecería razonable que el plazo durante el cual se mantuvieron estas medidas de excepción sea tomado en consideración por los órganos jurisdiccionales ante los cuales se invoque la violación al principio de duración razonable del procedimiento, como una causa de justificación de la Administración. Obviamente que dicha contemplación no podrá ser utilizada para amparar cualquier demora, ni plazos que hayan vulnerado el parámetro de razonabilidad independientemente de la emergencia sanitaria.

\section{BIBLIOGRAFÍA CONSULTADA.}

CAJARVILLE PELUFFO, Juan Pablo (2008a). Sobre Derecho Administrativo. Tomo II. Montevideo: Fundación de Cultura Universitaria.

CAJARVILLE PELUFFO, Juan Pablo (2008b). Recursos administrativos. Montevideo: Fundación de Cultura Universitaria.

DURÁN MARTÍNEZ, Augusto (2007). Contencioso administrativo. Montevideo: Fundación de Cultura Universitaria.

DURÁN MARTÍNEZ, Augusto. Derecho administrativo. Otra forma de verlo (2017). Montevideo: La Ley Uruguay.

DELPIAZZO, Carlos E. Derecho Administrativo General (2013). Montevideo: Amalio M. Fernández. 
ROTONDO TORNARÍA, Felipe. Manual de Derecho Administrativo (2015). Montevideo: Tradinco S.A.

Fecha de recepción: 31 de mayo 2020.

Fecha de aceptación: 20 junio 2020. 